\title{
Modern contraceptives discontinuation, method switching and associated factors among clients at the family planning clinic of a tertiary hospital in Port-Harcourt, Nigeria
}

\author{
Peter A. Awoyesuku*, Basil O. Altraide, Simeon C. Amadi
}

Department of Obstetrics and Gynaecology, Rivers State University Teaching Hospital, Port-Harcourt, Nigeria

Received: 28 October 2020

Accepted: 05 December 2020

*Correspondence:

Dr. Peter A. Awoyesuku,

E-mail: pawoyesuku@yahoo.co.uk

Copyright: () the author(s), publisher and licensee Medip Academy. This is an open-access article distributed under the terms of the Creative Commons Attribution Non-Commercial License, which permits unrestricted non-commercial use, distribution, and reproduction in any medium, provided the original work is properly cited.

\begin{abstract}
Background: Contraceptive discontinuation and switching to less effective methods, often leads to unintended pregnancies and reduces the impact of family planning programs. To understand what drives contraceptive use behavior, it is important to identify factors that influence discontinuation and switching. This study sought to determine the discontinuation rates, reasons for discontinuation or switching, and assess associated factors among women in Port Harcourt.

Methods: A retrospective descriptive study, of women 15-48 years who accepted a modern method, over a five-year period from $1^{\text {st }}$ January 2014 to $31^{\text {st }}$ December 2018 was carried out. Information on age, parity, education, contraceptive use intention, method and duration of use, reason for discontinuation, and method switching, were extracted from their hospital records. Coded data were entered into Excel spreadsheet and exported to SPSS version 20 for statistical analysis at significance level of $\mathrm{P}<0.05$.

Results: There were 349 women with complete data. Their mean age was $32 \pm 56$ years and median parity was 3 . The all-method discontinuation rate was $29.0 \%$ at 12 months and $31.5 \%$ by 24 months. Method specific discontinuation at 12 months were injectables $53.3 \%$, IUCD $38.2 \%$ and implants $23.8 \%$, the difference was significant $\mathrm{P}=0.018$. Reasons for discontinuation were reduced need-64.5\%, method problems-26.8\% and expiration-7.2\%. Majority $79.7 \%$ abandoned further use, $6.5 \%$ renewed their method and $13.8 \%$ switched to other methods.

Conclusions: The discontinuation rate was high, with associated poor switching behaviour. Proper counseling on contraceptive options and reinforcing switching are critical to reduce unwanted pregnancies that might result from poor method use and discontinuation.
\end{abstract}

Keywords: Associated factors, Contraceptive discontinuation, Family planning, Method switching, Port-Harcourt

\section{INTRODUCTION}

The World Health Organization (WHO) defines contraceptive prevalence rate as the percentage of women who are currently using at least one method of contraception, regardless of the method used. ${ }^{1}$ It is usually reported for married women aged 15 to 49 years. Globally this has increased from 55\% in 1990 to $64 \%$ in 2015. Contraceptive use in West Africa lags other regions of the world with an average of $15.3 \%$ of married women aged 15-49 years using any form of contraception. ${ }^{2}$

However, about $12 \%$ of women worldwide who want to delay or avoid pregnancy are not using any method of contraception (unmet needs) and this is much higher in low- and medium-income countries, especially in subSaharan African countries, put at $24 \%$. $^{3}$ The importance of supporting continued contraceptive use was shown in 
an analysis of data from 34 countries, which estimated that $38 \%$ of women with unmet needs were prior method users who discontinued for one reason or another. ${ }^{4}$ Another analysis of data from 36 countries found that about one-third of unintended recent births were attributable to contraceptive discontinuation. ${ }^{5}$

Contraceptive methods are generally categorized as either modern or traditional. The most acceptable modern methods are the pill, injectables, intrauterine devices (IUDs) and implants. Others are male/female sterilization, male/female condoms, lactational amenorrhea and emergency contraception, while the traditional methods are rhythm or calendar and withdrawal method. ${ }^{6}$ A recent study on contraceptive choices and acceptability in Port Harcourt revealed the most common method as implants $(70.2 \%)$, followed by IUDs $(25.8 \%)$, injectables $(3.2 \%)$ and oral pills $(0.8 \%){ }^{7}$ The study also revealed the use intention of $56 \%$ for completed family size (limiting) as against $44 \%$ for pregnancy prevention/spacing.

Contraceptive discontinuation is the phenomenon of starting a contraceptive method and then stopping it within one year of its use. Actual discontinuation rates vary by country and by method. An analysis of demographic and health survey data from 25 countries conducted between 1990 and 2009 found the all-method discontinuation rate to be $38 \%$ within the first year of use and $55 \%$ by the second year. ${ }^{8}$ The discontinuation of contraceptive methods occurs more with the methods that can be passively discontinued, such as condoms, injectable, pills and traditional methods as compared to the methods needing active discontinuation, such as the implants and intrauterine devices (IUD).$^{8-11}$ In low- and medium-income countries discontinuation often leads to unintended pregnancies and reduces the impact of family planning programs. ${ }^{12,13}$

The main reasons for contraceptive discontinuation are method failure, switching, abandoning use with no further need of contraception and abandoning use while still in need of contraception. Access to care and adverse reactions/unpleasant effects are important reasons for discontinuation. ${ }^{14,15}$ Studies have revealed socioeconomic and demographic factors such as age, parity, marital status, income, partner involvement in decision making and service quality were associated with the likelihood of contraceptive discontinuation. ${ }^{11,14,16}$ Older women and women at higher parities are more likely than younger and lower parity women to discontinue use while still in need.

Switching behavior following a discontinuation focuses on whether the switch resulted in the adoption of an equally, more, or less effective method than the one discontinued. Switching to less effective methods may expose women to a greater risk of unwanted pregnancies. While a high level of method switching could be a concern from the perspective of the discontinued method, it may also be a positive marker for the program's capacity to provide alternative methods to users. Switching increases with parity since women who are using contraception for spacing purposes tend to switch from short-term to long-term or terminal methods. Switching from one method to another increases the likelihood that the user will make another switch in the future. ${ }^{17}$

To fully understand what drives contraceptive use behavior, it is important to identify the factors that influence contraceptive use, discontinuation and/or switching to other methods. The study therefore sought to calculate the overall and method-specific discontinuation rates, examine reasons given for discontinuation or switching, and assess the characteristics associated with contraceptive switching and abandonment among women in Port Harcourt. This will facilitate successful family planning programs that promote not only acceptance of methods but also guide interventions that encourage sustained and continued use.

\section{METHODS}

This study was conducted at the family planning clinic of the Rivers State University Teaching Hospital (RSUTH), a tertiary hospital owned and funded by the Government of Rivers State. The hospital provides family planning counselling and services to clients from all over Port Harcourt city, as well as women who were delivered in the hospital. The hospital provides free services except in a few instances where the clients may pay a little token for certain consumables. The clinic provides all forms of modern contraceptives and has qualified providers trained in insertion and removal of implants and IUDs. The clinic runs daily, Mondays through Fridays.

A retrospective descriptive study over a five-year period from $1^{\text {st }}$ January 2014 to $31^{\text {st }}$ December 2018 was carried out. The study population were all women, 15-49 years, who started a modern contraceptive method and discontinued the methods on request or on provider recommendation at the family planning clinic. All women with regular follow-up and complete records were included, while those with incomplete data or that were lost to follow up were excluded.

Data were retrieved from the hospital records and case notes of all the women using a proforma data sheet. Information on maternal age, parity, educational status, contraceptive use intention (spacing or limiting), method chosen and duration of use, reason for discontinuation, method switching or abandonment, were extracted.

Coded data were entered into Excel spreadsheet and exported to SPSS version 20 for statistical analysis. Categorical measurements were given as numbers and percentages, and numerical measurements as mean and standard deviation. The Chi-square and ANOVA test were used for statistical analysis and statistical significance was set at $\mathrm{p}<0.05$. 


\section{RESULTS}

A total of 517 women accepted a modern method of contraception within the five-year study period, of which 168 women were lost to follow up with incomplete data and were excluded, the 349 women with complete data formed the study population in the analysis. Table 1 shows the socio-demographic characteristics of the women. The mean age \pm SD was $32 \pm 56$ (range 19-48) and the median parity was 3 (range 0-9). Majority of the women $59.6 \%$ were aged 31-40 years, $63.0 \%$ had Secondary education and $72.8 \%$ had parity of $2-4$.

Table 1: Socio-demographic characteristics of women attending the FPC at a tertiary hospital $(n=349)$.

\begin{tabular}{|lll|}
\hline Variables & \multicolumn{1}{l|}{ Frequency } & Percentage \\
\hline Age in years & 5 & 1.4 \\
\hline$\leq 20$ & 120 & 34.4 \\
\hline $21-30$ & 201 & 59.6 \\
\hline $31-40$ & 23 & 6.6 \\
\hline$>40$ & & \\
\hline $\begin{array}{l}\text { Mean } \pm \text { SD }=32.56 \pm 5.10 \\
\text { Range=19-48 years }\end{array}$ & & \\
\hline Educational level & 3 & 0.9 \\
\hline None & 25 & 7.2 \\
\hline Primary & 220 & 63.0 \\
\hline Secondary & 101 & 28.9 \\
\hline Tertiary & & \\
\hline Parity & 2 & 0.6 \\
\hline Para 0 & 27 & 7.7 \\
\hline Para 1 & 254 & 72.8 \\
\hline Para 2 -4 & 65 & 18.9 \\
\hline Para $\geq 5$ & \\
\hline Median =Para 3; Range & Para 0 - 9 \\
\hline
\end{tabular}

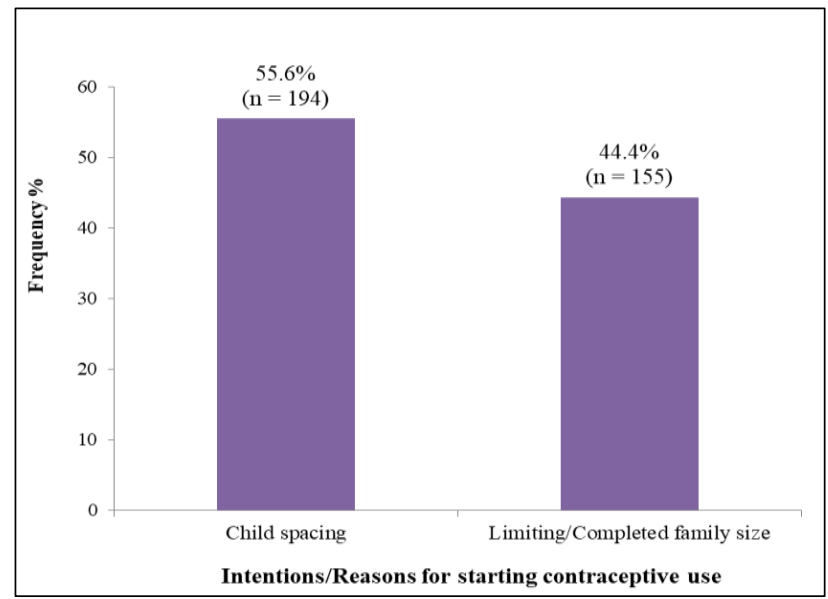

Figure 1: Intentions for starting contraceptive use among women attending FPC of a tertiary hospital.

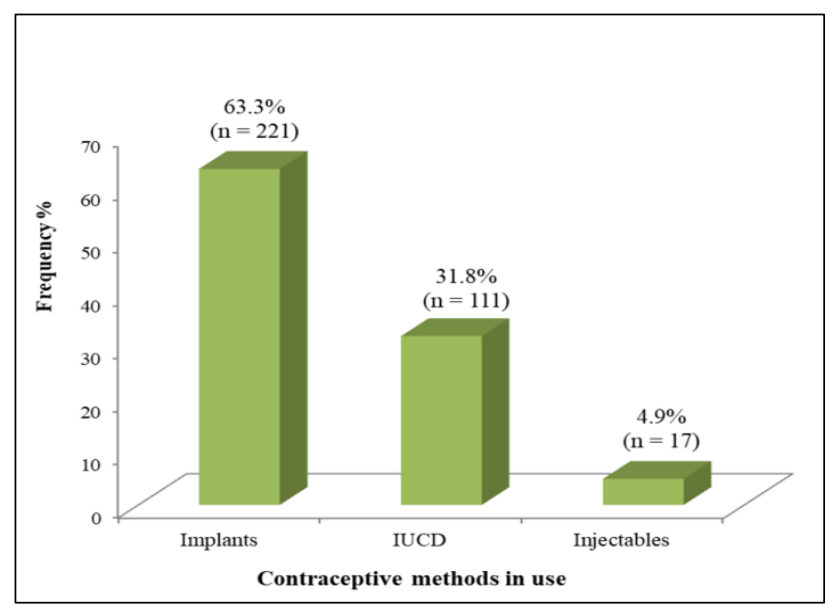

Figure 2: Methods of contraceptive use among women attending the FPC of a tertiary hospital.

Table 2: Method-specific contraceptive discontinuation rates among women attending the FPC of a tertiary hospital.

\begin{tabular}{|c|c|c|c|c|c|}
\hline & \multicolumn{5}{|c|}{ Duration of use } \\
\hline $\begin{array}{l}\text { Contraceptive } \\
\text { methods }\end{array}$ & $\begin{array}{l}<12 \text { months } \\
N(\%)\end{array}$ & $\begin{array}{l}12-24 \text { months } \\
\text { N }(\%)\end{array}$ & $\begin{array}{l}>24-36 \text { months } \\
N(\%)\end{array}$ & $\begin{array}{l}>36 \text { months } \\
N(\%)\end{array}$ & $\begin{array}{l}\text { Total } \\
\text { N }(\%)\end{array}$ \\
\hline Implants & $46(23.8)$ & $65(33.7)$ & $57(29.5)$ & $25(13.0)$ & $193(100.0)$ \\
\hline IUCD & $26(38.2)$ & $16(23.5)$ & $17(25.0)$ & $9(13.2)$ & $68(100.0)$ \\
\hline Injectables & $8(53.3)$ & $6(40.0)$ & $0(0.0)$ & $1(6.7)$ & $15(100.0)$ \\
\hline All methods & $80(29.0)$ & $87(31.5)$ & $74(26.8)$ & $35(12.7)$ & $276(100.0)$ \\
\hline
\end{tabular}

Fisher's exact test $=14.620 ; \mathrm{p}$-value $=0.018^{*},{ }^{*}$ statistically significant $(\mathrm{p}<0.05)$

A slight majority $194(55.6 \%)$ of the women had child spacing as their contraceptive use intention, while the other 155 women $(44.4 \%)$ was for limiting or completed family size (Figure 1). Majority of the users $221(63.3 \%)$ accepted implants (Implanon and Jadelle), followed by IUCD (copper T) $111(31.8 \%)$ and injectables (DepoProvera and Noristerat) $17(4.9 \%)$ see Figure 2. The allmethod discontinuation rate was $29.0 \%$ at 12 months and increased to $31.5 \%$ by 24 months, then fell to $26.8 \%$ by 36 months and thereafter only $12.7 \%$ discontinued use (Table 3). The method-specific discontinuation rate at 12 months was highest for injectables $53.3 \%$ of acceptors, followed by IUCD $38.2 \%$ and implants $23.8 \%$. At 24 months injectables was also highest at $40.0 \%$, followed by Implants at $33.7 \%$ and IUCD at $23.5 \%$ of acceptors (Table 2). The differences in the discontinuation rates was found to be statistically significant $(\mathrm{P}=0.018)$. 
Table 3: Reasons for contraceptive discontinuation among women attending the FPC of a tertiary hospital.

\begin{tabular}{|lllll|}
\hline & \multicolumn{2}{l}{ Contraceptive methods in use } \\
\hline Reasons for discontinuation & $\begin{array}{l}\text { Implants } \\
\text { IUCD }\end{array}$ & $\begin{array}{l}\text { Injectables } \\
\text { All methods }\end{array}$ \\
\hline Reduced need & $124(67.0)$ & $47(25.4)$ & $14(7.6)$ & $185(100.0)$ \\
\hline Method problems/complications & $49(73.1)$ & $17(25.4)$ & $1(1.5)$ & $67(100.0)$ \\
\hline Expired & $19(95.0)$ & $1(5.0)$ & $0(0.0)$ & $20(100.0)$ \\
\hline Method failure/became pregnant while using & $1(100.0)$ & $0(0.0)$ & $0(0.0)$ & $1(100.0)$ \\
\hline Lack of sexual satisfaction for partner & $0(0.0)$ & $3(100.0)$ & $0(0.0)$ & $3(100.0)$ \\
\hline Total Number of discontinuations & $193(69.9)$ & $68(24.6)$ & $15(5.4)$ & 276 \\
$(0.0)$
\end{tabular}

Fisher's exact test $=18.054 ; \mathrm{p}$-value $=0.012 *{ }^{*}$ statistically significant $(\mathrm{p}<0.05)$

Table 4: Factors associated with contraceptive discontinuation among women attending the FPC at a tertiary hospital.

\begin{tabular}{|c|c|c|c|}
\hline \multicolumn{4}{|c|}{ Contraceptive discontinuation } \\
\hline Variables $(N=349)$ & $\begin{array}{l}\text { Yes } \\
\text { N (\%) }\end{array}$ & $\begin{array}{l}\text { No } \\
\text { N (\%) }\end{array}$ & $\begin{array}{l}\text { Total } \\
\text { N }(\%)\end{array}$ \\
\hline \multicolumn{4}{|l|}{ Age in years } \\
\hline$\leq 20$ & $5(100.0)$ & $0(0.0)$ & $5(100.0)$ \\
\hline $21-30$ & $109(90.8)$ & $11(9.2)$ & $120(100.0)$ \\
\hline $31-40$ & $147(73.1)$ & $54(26.9)$ & $201(100.0)$ \\
\hline$>40$ & $15(65.2)$ & $8(34.8)$ & $23(100.0)$ \\
\hline \multicolumn{4}{|c|}{ Fisher's exact test $=18.984 ; \mathrm{p}$-value $=0.0001 *$} \\
\hline \multicolumn{4}{|c|}{ Educational level } \\
\hline None & $2(66.7)$ & $1(33.3)$ & $3(100.0)$ \\
\hline Primary & $18(72.0)$ & $7(28.0)$ & $25(100.0)$ \\
\hline Secondary & $179(81.4)$ & $41(18.6)$ & $220(100.0)$ \\
\hline Tertiary & $77(76.2)$ & $24(23.8)$ & $101(100.0)$ \\
\hline \multicolumn{4}{|c|}{ Fisher's exact test $=2.866 ; \mathrm{p}$-value $=0.387$} \\
\hline \multicolumn{4}{|c|}{ Parity } \\
\hline Para 0 & $1(50.0)$ & $1(50.0)$ & $2(100.0)$ \\
\hline Para 1 & $27(100.0)$ & $0(0.0)$ & $27(100.0)$ \\
\hline Para $2-4$ & $208(81.9)$ & $46(18.1)$ & $254(100.0)$ \\
\hline Para $\geq 5$ & $40(60.6)$ & $26(39.4)$ & $66(100.0)$ \\
\hline \multicolumn{4}{|c|}{ Fisher's exact test $=23.9694 ; \mathrm{p}$-value $=0.0001^{*}$} \\
\hline \multicolumn{4}{|c|}{ Contraceptive use Intention } \\
\hline Spacing & $183(94.3)$ & $11(5.7)$ & $194(100.0)$ \\
\hline Limiting & $93(60.0)$ & $62(40.0)$ & $194(100.0)$ \\
\hline
\end{tabular}

*Statistically significant $(\mathrm{p}<0.05)$

The major reason for discontinuation of all methods was reduced need $178(64.5 \%)$ - of which desired pregnancy was $118(42.8 \%)$, menopause/pre-menopause was 2 $(0.7 \%)$, misconception was $1(0.4 \%)$, removal on request was $57(20.7 \%)$. This was followed by method problems/complications $43(26.8 \%)$ - amenorrhea 7 (2.5\%), body itching $2(0.7 \%)$, dyspareunia $1(0.4 \%)$, infection/re-infection $5(1.8 \%)$, irregular/prolonged/ severe bleeding $32(11.6 \%)$, medical complication 18 (6.5\%), missing IUCD $2(0.7 \%)$, waist pain $2(0.7 \%)$, weight gain $5(1.8 \%)$. Third most common reason for discontinuation was expiration of the chosen method 20
(7.2\%), Then lack of sexual satisfaction for partner 3 $(1.1 \%)$, and method failure (became pregnant while using the method) $1(0.4 \%)$.

Table 3 shows the reasons for discontinuation of the individual methods and the difference for the various methods was statistically significant $(\mathrm{P}=0.012)$. Table 4 shows the factors associated with discontinuation of contraceptives among the study population and revealed a statistically significant relationship with age of the women $(\mathrm{P}=0.0001)$, parity $(\mathrm{P}=0.0001)$ and contraceptive use intention $(\mathrm{P}=0.0001)$, but not educational status $(\mathrm{P}=0.387)$. 
Table 5: Behaviour following discontinuation among women attending the FPC of a tertiary hospital.

\begin{tabular}{|lllll|}
\hline $\begin{array}{l}\text { Methods } \\
\text { discontinued }\end{array}$ & $\begin{array}{l}\text { Next event after discontinuation } \\
\text { usage } \mathbf{N}(\boldsymbol{\%})\end{array}$ & $\begin{array}{l}\text { Renewed } \\
\mathbf{N}(\boldsymbol{\%})\end{array}$ & $\begin{array}{l}\text { Switched to another } \\
\text { method N }(\boldsymbol{\%})\end{array}$ & $\begin{array}{l}\text { Total } \\
\mathbf{N}(\boldsymbol{\%})\end{array}$ \\
\hline Implants & $155(80.3)$ & $16(8.3)$ & $22(11.4)$ & $193(100.0)$ \\
\hline IUCD & $57(83.8)$ & $2(2.9)$ & $9(13.2)$ & $68(100.0)$ \\
\hline Injectables & $8(53.3)$ & $0(0.0)$ & $7(46.7)$ & $15(100.0)$ \\
\hline All methods & $220(79.7)$ & $18(6.5)$ & $38(13.8)$ & $276(100.0)$ \\
\hline
\end{tabular}

Fisher's exact test $=12.613 ; \mathrm{p}$-value $=0.009 * *$ Statistically significant $(\mathrm{p}<0.05)$

Table 6: Contraceptive methods switched to following discontinuation among women attending the FPC of a tertiary hospital.

\begin{tabular}{|lll|}
\hline $\begin{array}{l}\text { Contraceptive methods } \\
\text { switched to }\end{array}$ & Frequency & Percentage \\
\hline Implants & 20 & 52.6 \\
\hline Implanon & 9 & 23.7 \\
\hline Jadelle & 11 & 28.9 \\
\hline IUCD & 4 & 10.5 \\
\hline Injectables & 8 & 21.1 \\
\hline Male condom & 5 & 13.2 \\
\hline Oral pills & 1 & 2.6 \\
\hline Total & 38 & 100.0 \\
\hline
\end{tabular}

Table 5 shows the behaviour of the women following discontinuation of their chosen methods. Majority of the women $220(79.7 \%)$ completely abandoned further use, of these 155 were implant acceptors (constituting $80.3 \%$ of all acceptors), followed by 57 IUCD acceptors (constituting $83.3 \%$ of all acceptors) and 8 injectables acceptors (constituting $53.3 \%$ of all acceptors). Eighteen women $(6.5 \%)$ renewed their method while 38 women
(13.8\%) switched to another contraceptive method. Methods switched to were implants 20 (52.6\%), injectables $8(21.1 \%)$, male condom $5(13.2 \%)$, IUCD 4 (10.5\%) and oral contraceptive pill (OCP) 1 (2.6\%), see Table 6. Based on contraceptive use intention, switching occurred in only $8.7 \%$ of women that are using it for child spacing, as against $23.7 \%$ of those that are limiting, and the difference was statistically significant at $\mathrm{P}=0.001$, Table 7. A comparison of the various methods and the switching behaviour for each method is as shown in Table 8 , and the differences were statistically significant $(\mathrm{P}=0.0001)$.

Table 7: Contraceptive use intention versus method switching among the women.

\begin{tabular}{|llll|}
\hline & \multicolumn{3}{l}{ Contraceptive method switch } \\
\hline Variables & Yes, N (\%) & No, N (\%) & Total, N (\%) \\
\hline Spacing & $16(8.7)$ & $167(91.3)$ & $183(100.0)$ \\
\hline Limiting & $22(23.7)$ & $71(76.3)$ & $93(100.0)$ \\
\hline Total & $38(13.8)$ & $238(86.2)$ & $276(100.0)$ \\
\hline
\end{tabular}

Chi Square $=11.550 ;$ p-value $=0.001 * *$ Statistically significant $(\mathrm{p}<0.05)$

Table 8: Switching behaviour following discontinuation among women attending the FPC of a tertiary hospital.

\begin{tabular}{|c|c|c|c|c|c|c|}
\hline \multicolumn{7}{|c|}{ Contraceptive methods switched to } \\
\hline $\begin{array}{l}\text { Methods } \\
\text { discontinued }\end{array}$ & $\begin{array}{l}\text { Implanon } \\
\mathbf{N}(\%)\end{array}$ & $\begin{array}{l}\text { Jadelle } \\
\mathbf{N}(\%)\end{array}$ & $\begin{array}{l}\text { IUCD } \\
\text { N }(\%)\end{array}$ & $\begin{array}{l}\text { Injectables } \\
\mathbf{N}(\%)\end{array}$ & $\begin{array}{l}\text { Male condom } \\
\mathbf{N}(\%)\end{array}$ & $\begin{array}{l}\text { Oral pills } \\
\mathbf{N}(\%)\end{array}$ \\
\hline Implanon & $0(0.0)$ & $6(40.0)$ & $4(26.7)$ & $4(26.7)$ & $0(0.0)$ & $1(6.7)$ \\
\hline Jadelle & $1(14.3)$ & $0(0.0)$ & $0(0.0)$ & $2(22.2)$ & $4(57.1)$ & $0(0.0)$ \\
\hline IUCD & $5(55.6)$ & $1(11.1)$ & $0(0.0)$ & $2(22.2)$ & $1(11.1)$ & $0(0.0)$ \\
\hline Injectables & $3(42.9)$ & $4(57.1)$ & $0(0.0)$ & $0(0.0)$ & $0(0.0)$ & $0(0.0)$ \\
\hline All methods & $9(23.7)$ & $11(28.9)$ & $4(10.5)$ & $8(21.1)$ & $5(13.2)$ & $1(2.6)$ \\
\hline
\end{tabular}

Fisher's exact test $=30.299 ; \mathrm{p}$-value $=0.0001 * *$ Statistically significant $(\mathrm{p}<0.05)$

\section{DISCUSSION}

Early discontinuation and not switching to another contraceptive method increases the risk of unplanned pregnancy. The all-method discontinuation rates of $29 \%$ in the first year and $31.5 \%$ by end of the second year found by this study, while being unacceptably high, was lower than the $38 \%$ and $55 \%$ respectively found in a tenyear survey conducted in 25 countries. $^{8}$ Actual discontinuation rates vary by country and by method. While the all-method discontinuation by 12 months has been reported to be $34.7 \%$ in urban Senegal, a study from Ghana reported $56 \%$, and one from rural Southwest Ethiopia reported $11.5 \% .^{18-20}$ The differences can only be explained by the study area, contraceptive acceptance and use intentions of the population studied.

The use intention in this study of $55.6 \%$ for child spacing was only slightly above half and might explain the lower discontinuation rate than the studies from Senegal and Ghana above. The lower likelihood of discontinuation among women who intend to limit births supports previous findings that the motivation to avoid pregnancy 
is a contributor to whether women abandon use of a contraceptive or not. ${ }^{21}$ This study found a significant association of discontinuation with use intention, with majority of the women who were using it for child spacing forming the group that discontinued use.

In studies of contraceptive discontinuation, the most important determinant highlighted has been the contraceptive method used. ${ }^{11}$ The Injectables was the most method discontinued in this study and is like the findings by Barden-O'Fallon et al. ${ }^{18}$ The discontinuation of contraceptive methods occurs more with the methods that can be passively discontinued, such as condoms, injectable, pills and traditional methods as compared to the methods needing active discontinuation, such as the implants and intrauterine devices (IUD). ${ }^{8,11}$ Other studies have also identified high discontinuation mostly among Pill and condom users, followed by injectables, and lower rates for methods such as IUDs and Implants. ${ }^{20,21}$

The most common reasons for discontinuation were reduced needs $(64.5 \%)$, method problems and side-effects constituting only $26.8 \%$. This is like the findings of Barden-O'Fallon et al, who reported $45.6 \%$ and $30.1 \%$ respectively. ${ }^{18}$ This study found a significant difference of discontinuations due to method problems/side-effects and the different methods, with Implants and IUD users constituting a majority. One study on IUD discontinuation rates has reported a rate of $19.4 \%$ in 10 months with $69.4 \%$ of them due to method problem/sideeffects. $^{22}$

This study also revealed that only few women (13.8\%) who discontinued use of a method switched to another method. This is not much different from the findings in similar studies of $17 \%$ by Barden-O'Fallon et al and $9.6 \%$ by Yideta et al. ${ }^{18,20}$ Some studies have however reported higher rates of switching following discontinuation, Azmat et all reported 36.3\% and Modey et al reported $55 \%$, but both studies were mainly on IUDs with reported reason for discontinuation majorly due to method problem/side-effects. ${ }^{22,19}$ The lower occurrence of method switching in this study may be suggestive of some challenges in counselling the patients on available choices and the option of switching. Studies have reinforced this view by suggesting that although women may be aware of their options, they may not have received enough information to decide to adopt alternative methods. ${ }^{23,24}$

Switching behavior following a discontinuation should focus on whether the switch resulted in the adoption of an equally, more, or less effective method than the one discontinued. Switching to less effective methods may expose women to a greater risk of unwanted pregnancies. In this study, majority of the switching occurred from injectables and IUDs (59.9\%) to implants (52.6\%), an equally or more effective long acting method. While a high level of method switching could be a concern from the perspective of the discontinued method, it may also be a positive marker for the program's capacity to provide alternative methods to users.

\section{CONCLUSION}

This study found a discontinuation rate that was high, with associated poor switching behaviour. Proper counseling on contraceptive options and reinforcing switching are critical to reduce unwanted pregnancies that might result from poor method use and discontinuation.

The general counselling given to women on presentation for contraceptive services should place more emphasis on experience of side-effects and how to manage them to improve adherence among women who accept methods and encourage women with such difficulties, who may still be in need of contraception, to present to the facility with such problems. This will encourage switching when such problems arise.

\section{ACKNOWLEDGMENTS}

Authors would like to thank Dr Yvonne W. Iwowari and Dr Chinenye Uche-Onu, internship doctors who voluntarily assisted in retrieving data from case notes and hospital registers at the family planning clinic.

\section{Funding: No funding sources \\ Conflict of interest: None declared \\ Ethical approval: The study was approved by the Institutional Ethics Committee of RSUTH (RSUTH/REC/2020030)}

\section{REFERENCES}

1. World Health Organization (WHO). Sexual and reproductive health: Contraceptive Prevalence, 2013. Available at: http://www.who.int/reproductivehealth/topics/family _planning/contraceptive_prevalence/en/. Accessed Feb 2020.

2. Statcompiler. The DHS Program. 2016. Available at: http://stacompiler.com/en/index.html. Accessed Feb 2020.

3. UNDESA. Trends in Contraceptive Use Worldwide, 2015. Available at: http://www.un/org/en/development/desa/population/ publications/pdf/family/trendsContraceptiveUse2015 Report.pdf. Accessed Feb 2020.

4. Jain AK, Obare F, RamaRoa S, Askew I. Reducing unmet need by supporting women with met need. Int Perspect Sex R H. 2013;39(3):133-41.

5. Jain AK, Winfrey W. Contribution of contraceptive discontinuation to unintended births in 36 developing countries. Studies Family Plann. 2017;48(3):269-78.

6. World Health Organization (WHO), 2012. Family planning factsheets No 351. Geneva, Switzerland.

7. Awoyesuku PA, Altraide BOA. Contraceptive Choices and Acceptability among New Clients 
Attending Family Planning Unit of Rivers State University Teaching Hospital, Nigeria. J Advan Med Med Res. 2019;30(3):1-7.

8. Ali MA, Cleland J, Causes SIH. Consequences of contraceptive discontinuation: evidence from 60 demographic and health surveys. Geneva, Switzerland: World Health Organization, 2012.

9. Barden-O'Fallon J, Speizer I. What differentiates method stoppers from switchers? Contraceptive discontinuation and switching among Honduran women. Int Perspect Sex R H. 2011;37(1):16-23.

10. Ravi F, Irfan G. Reasons for discontinuation of contraceptive methods among couples with different family size and educational status. J Ayub Med Abbottabad. 2012;24(1):101-4.

11. Ali MM, Cleland J. Oral contraceptive discontinuation, and its aftermath in 19 developing countries. Contraception. 2010;81(1):22-9.

12. Why Do Women and Girls Stop Using Contraceptives?, 2016. Available at: http://globaldaily.com/why-do-women-and-girlsstop-using-contraceptives/.

13. The Leaking Bucket Phenomenon in Family Planning, 2014. Available at: http://champions4choice.org/2014/09/the-leakingbucket-phenomenon-in-family-planning/.

14. Blanc AK, Curtis SL, Croft TN. Monitoring contraceptive continuation: links to fertility outcomes and quality of care. Stud Fam Plan. 2002;33(2):127-40.

15. Khan MA. Side effects and oral contraceptive discontinuation in rural Bangladesh. Contraception. 2001;64(3):161-7.

16. World Health Organization, 2012. Contraception discontinuation and switching in developing countries Research policy brief. Available at: https://www.who.int/reproductivehealth/publications /family_planning/rhr_12_15/en/.

17. Ferguson AG. Fertility and Contraceptive Adoption and Discontinuation in Rural Kenya. Stud Fam Plan. 1992;23(4):257-67.
18. Barden-O'Fallon J, Speizer IS, Calhoun LM, Corroon M. Women's contraceptive discontinuation and switching behaviour in urban Senegal, 20102015. BMC Women's Health. 2018;18:35-43.

19. Modey EJ, Aryeetey R, Adanu R. Contraceptive Discontinuation and Switching Among Ghanaian Women: Evidence from the Ghana Demographic and Health Survey, 2008. African J Reprod Heal. 2014;18(1):84-92.

20. Yideta ZS, Mekonen L, Seifu W, Shine S. Contraceptive Discontinuation, Method Switching and Associated Factors among Reproductive Age Women in Jimma Town, Southwest Ethiopia, 2013. Fam Med Med Sci Res. 2017;6:213.

21. Curtis S, Evens E, Sambisa W. Contraceptive Discontinuation and Unintended Pregnancy: An Imperfect Relationship. Intern Perspect Sexual Reproduct Health. 2011;37(2):58-66.

22. Azmat SK, Hameed W, Mustafa G, Hussain W, Ahmed A, Bilgrami M. IUD discontinuation rates, switching behaviour, and user satisfaction: findings from a retrospective analysis of a mobile outreach service program in Pakistan. Intern J Women's Health. 2013;5:19-27.

23. Ali MM, Cleland J. Contraceptive Switching after Method-related Discontinuation: Levels and Differentials. Studies in Family Planning. 2010;41(2):129-33.

24. World Health Organization. Contraception discontinuation and switching in developing countries. In: Research DoRha, editor. Geneva: WHO, 2012:4.

Cite this article as: Awoyesuku PA, Altraide BO, Amadi SC. Modern contraceptives discontinuation, method switching and associated factors among clients at the family planning clinic of a tertiary hospital in Port-Harcourt, Nigeria. Int J Reprod Contracept Obstet Gynecol 2021;10:5-11. 